\title{
Spatial Temporal Analysis of Land Use Change in the Shiyang River Basin in Arid China, 1986-2015
}

\author{
Wei Wei ${ }^{1}$, Yaowen Xie ${ }^{1 *}$, Peiji Shi², Junju Zhou' ${ }^{2}$ Chuanhua Li \\ ${ }^{1}$ College of Earth and Environmental Sciences, Lanzhou University, \\ Lanzhou, 730000, China \\ ${ }^{2}$ College of Geography and Environmental Science, Northwest Normal University, \\ Lanzhou 730070, China
}

Received: 4 November 2016

Accepted: 8 February 2017

\begin{abstract}
The Shiyang River Basin has been regarded as an important ecological protective area in the Hexi corridor in northwest China. Landsat TM, ETM+, and OLI images in 1986, 2000, 2006, and 2015 were selected as basic data resources, and the circle layers and fan-shaped analysis were applied to extract change information and the characteristics of land use pattern change by a set of transfer and dynamic models. Results showed that urban and residential land expanded $176.7 \mathrm{~km}^{2}$, which was about $48.57 \%$ in the past 30 years, and that the woodland and grassland decreased $7.24 \%$ and $1.39 \%$, respectively. It was found that woodland mainly distributed in the range of elevation from 2,500 to 4,000 m, and unused land was distributed in the downstream plain, which was an average elevation of 1,500 meters below. Moreover, the area and spatial distribution of land use were influenced by human activities and resulted in fundamental changes of pattern. We found that spatiotemporal pattern analysis of land use cover was essential for understanding the structure and characteristics of urbanization and the local eco-environment.
\end{abstract}

Keywords: arid area, spatiotemporal analysis, land use change, Shiyang River Basin

\section{Introduction}

Land use and land cover change (LUCC) has become an important and hot theme in the study field of global environmental change since the Global Environmental Change in the Humanities Program (IHDP) and the International Geosphere-Biosphere Program (IGBP) put forward the LUCC research project [1-2]. LUCC has great significance regarding the function of ecosystems

*e-mail: xieyw@1zu.edu.cn and ecosystem services [3], and hydrologic processes [4]. Besides, it has a direct impact on biosphere-atmosphere interactions, biodiversity, surface radioactive forcing, biogeochemical cycles, and the sustainable utilization of environmental resources [5].

Many researchers have found that within the Shiyang River Basin, the extent of land use change resulting from urban expansion and sprawl between 2000 and 2010 could not be adequately explained by one factor alone [6]. Similarly, Zhang et al. [7], using Landsat/ETM data, population data, and economic statistical data analyzed the land use change pattern, and the major driving 
forces of the land use change in Shiyang River Basin. Researchers obtained the land use change areas, ratios, speed from multi-temporal images, statistic data, and field investigation [8]. However, these techniques cannot effectively identify the impacts of land use change in a spatial context, and the class conversions cannot displayed through figures. In this context, the availability of spatial data at regular intervals through space-borne remote sensors is helpful in effectively detecting and monitoring rapid land use changes [9-10].

Sequences of land use changes, either directions or layers, may reveal important details in different zones and directions. Circle layer analysis was used to understand the pattern of different zones from basin centre to outside. The land use change of every zone was calculated and displayed through the circle gradient. Fan-shaped analysis was also used to compute the change area in 16 directions for different periods. Furthermore, distribution zones of land use were carried out with area statistics based on different regions according to elevation features in GIS. The main objective of this paper is to present the results of an analysis comparing the spatial and temporal patterns of land use change in arid inland regions of northwest China. Specific research addressed here includes:

1. Where are the land use classes distributed across different elevation partitions?

2. What are the patterns of land use distribution in different locations and directions?

3. What are the speeds of land use change in the four periods?

\section{Material and Methods}

\section{Study Area}

The Shiyang River Basin $\left(101^{\circ} 22^{\prime}-104^{\circ} 16^{\prime} \mathrm{E}\right.$ and $36^{\circ} 29^{\prime}-39^{\circ} 27^{\prime} \mathrm{N}$ ) is one of the three inland river basins in the Hexi corridor, lying east of the corridor in Gansu

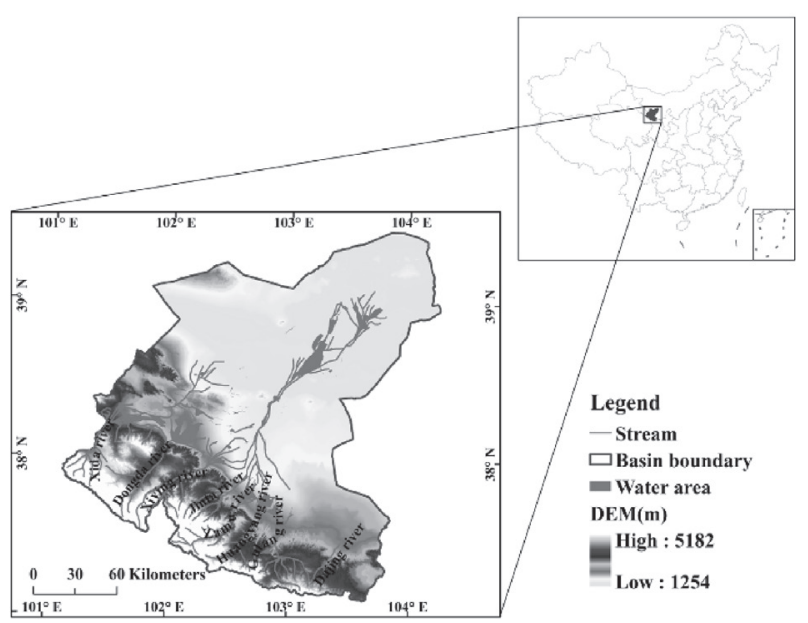

Fig. 1. The location of the Shiyang River Basin in northwest China.
Province in northwest China (Fig. 1). The basin occupies an area of $4.16 \times 104 \mathrm{~km}^{2}$ and includes seven counties [11]. It is located in a continental temperate zone with arid climate and variable topography. The annual precipitation is $100-600 \mathrm{~mm}$, whereas the annual pan evaporation is $700-2,600 \mathrm{~mm}$. The Shiyang River originates from the Qilian Mountains with eight tributaries, which are mainly fed by rainfall, snowmelt, and glacier melt in the Qilian Mountains. The total water resource is $16.61 \times 10^{8} \mathrm{~m}^{3}$, of which surface runoff is about $15.61 \times 10^{8} \mathrm{~m}^{3}$ and groundwater is $1.00 \times 10^{8} \mathrm{~m}^{3}$.

\section{Remote Sensing and Data Processing}

Four time periods of Landsat TM/ETM images were acquired to detect the spatial temporal change of land use from 1986 to 2015. They were Landsat TM images of 1986 and 2000, Landsat ETM+ of 2006, and Landsat OLI of 2015 (spatial resolution is $30 \mathrm{~m} \times 30 \mathrm{~m}$ ). Besides, SPOT images of 2000 (spatial resolution is $10 \mathrm{~m}$ ) and Google Earth screenshots (September 2015) were obtained to help identify land use class and boundary. Other data included digital elevation model (DEM) with a spatial resolution of $30 \times 30 \mathrm{~m}$, and the land use maps at a scale of 1:100 000 from 2006 and 2015. DEM is provided by the Geospatial Data Cloud (www.gscloud.cn), the Computer Network Information Center, and the Chinese Academy of Sciences. Land use maps come from the Cold and Arid Regions Sciences Data Center at Lanzhou (westdc. westgis.ac.cn). The remote sensing data obtained were geo-referenced, rectified, and cropped pertaining to the study area and to minimize geographical deviation [12]. Geo-referenced remote sensing data (Landsat data) has been done using ground control points collected from the field using GPS, and also from known points (e.g., street corners or road intersections).

In this study, all the pre-processed images were manually classified using a geographical information system through grid-based visual interpretation [12]. Land use was classified using six categories, including farmland, woodland, grassland, water body, urban, and residential land, and unused land according to the land use classification standard by the Chinese Academy of Sciences [13]. After that, the classification comparison approach and field observations were used to assess land use change detection. Accuracy assessment to evaluate the classification result was done with the help of training samples and field data by testing the statistical significance of a difference and computation of kappa coefficients [14]. The Kappa coefficients of 1986, 2000, 2006, and 2015 were $79.56 \%, 80.20 \%, 83.84 \%$, and $88.44 \%$, respectively - all good enough to contrast with the others.

\section{Land Use Change Detection Methods}

\section{Land Use Distribution in Elevation Partition}

The study area is located in the three major loess transition zones of the Loess, Tibetan, and Mongolian 
plateaus, and the elevation is very different from downstream to upstream. Different land use classes have obvious zonal differentiation characteristics. To analyze the different land use classes at different altitudes within the scope of distribution (e.g., where are the farmland and the woodland main distributions? What are the differences in the distribution area?), the region has been divided into nine elevation partitions (EP) based on digital elevation models (DEM) of 1,200-1,500 m (I), 1,500-2,000 m (II), 2,000-2,500 m (III), 2,500-3,000 m (IV), 3,000-3,500 m (V), 3,500-4,000 m (VI), 4,000-4,500 m (VII), 4,5005,000 m (VIII), and 5,000-5,200 m, respectively, based on the terrain and geomorphic features of the study area.

\section{Circle-Layer Analysis}

Land use was divided into concentric circles of incrementing radius of $15 \mathrm{~km}$ from the centre of the city (Fig. 2a), which would help in visualizing and understanding the agents responsible for changes at the local level. This approach (circle layers) also helps in visualizing the forms

a)

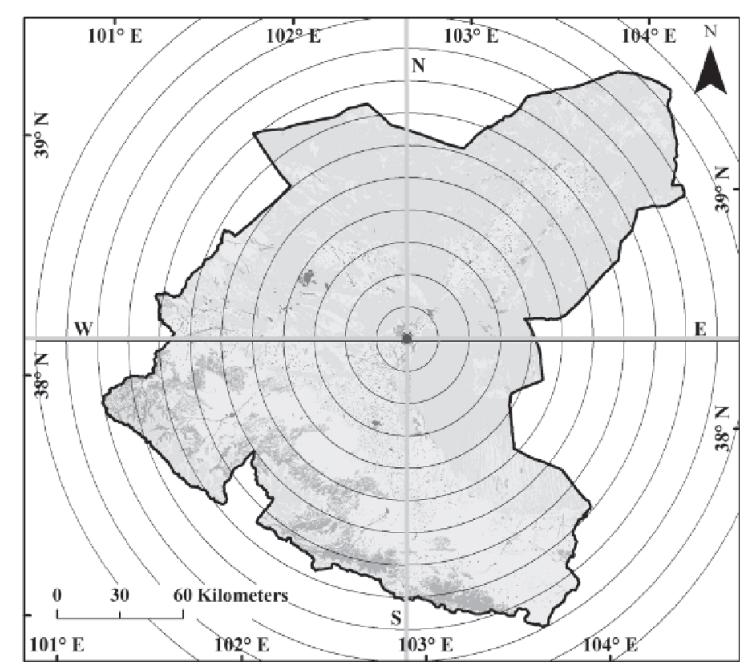

b)

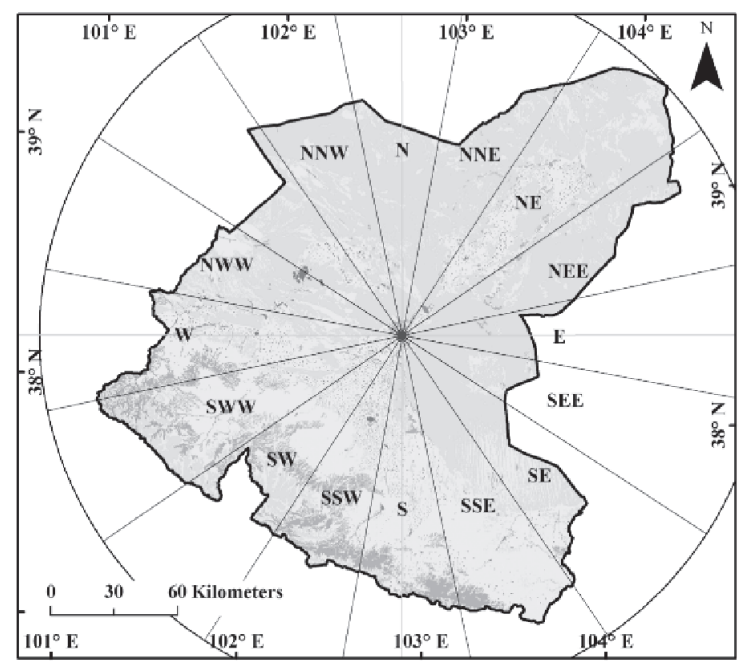

Fig. 2. Circle layers and fan-shaped structures and overlay land use classes. of land use change (increase, decrease, sprawl, compact, etc.) and the structural characteristics of land use through building the circle buffer, which had an equal radius [15]. The area change ratio in each circle is monitored overtime using time series analysis. The land use region had 12 circle layers to cover the entire study area. In the process of calculation area in each circle layer, the land use in 1986, 2000, 2006, and 2015 was clipped by circle layers respectively in ArcGIS.

\section{Fan-Shaped Analysis}

Land use pattern has not been uniform in all directions. To understand the pattern of change in different directions, the region has been divided into 16 zones based on the directions: north $(\mathrm{N})$, north-northeast (NNE), northeast (NE), northeast-east (NEE), east(E), southeast-east (SEE), southeast (SE), south-south east, south (S), south-southwest (SSW), southwest (SW), southwest-west (SWW), west (W), northwest-west (NWW), northwest (NW), northnorthwest (NNW), and north (N), respectively (Fig. 3b) based on the central pixe (geo-spatial central). Each zone was seen as a fan-shape and had equal area. The change of the land use classes in respective zones was monitored through the computation of area for different periods. The fan-shaped area covered about a $170-\mathrm{km}$ radius, which could contain the entire study region (Fig. 2b).

\section{Land Use Dynamicity Analysis}

The quantitative change of land use can be represented by land use dynamicity, including single land use dynamicity and comprehensive land use dynamicity. It refers to the quantitative change of one single land use class in a study region at a certain period of time. This paper used single land use dynamicity, which can be calculated as:

$$
R_{d}=\left(U_{b}-U_{d}\right) / U_{a} \times 1 / T \times 100 \%
$$

...where $R_{d}$ represents the dynamicity of one land use class over the period; $U_{a}$ and $U_{b}$ denote the areas of one land use class at the beginning (moment a) and at the end (moment b) of the study period, respectively; and T stands for the study period from moment a to moment $\mathrm{b}$. If $\mathrm{T}$ is set to be multiple years, the value of $R_{d}$ will be the annual changing rate of the land use class during the given period.

For a land use class, the land change can be described using the ratio of area change in a region to the total area of study area over a time period. To reflect the increase and decrease degree of a land use class, the index of change magnitude of land use was used to calculate. It can be defined as:

$$
I_{d}=\left(U_{b}-U_{d}\right) / A_{l} \times 1 / T \times 100 \%
$$

...where $I_{d}$ represents the index of change magnitude of land use class over the period and $\mathrm{A}_{1}$ denotes the total area of study area. 
a)
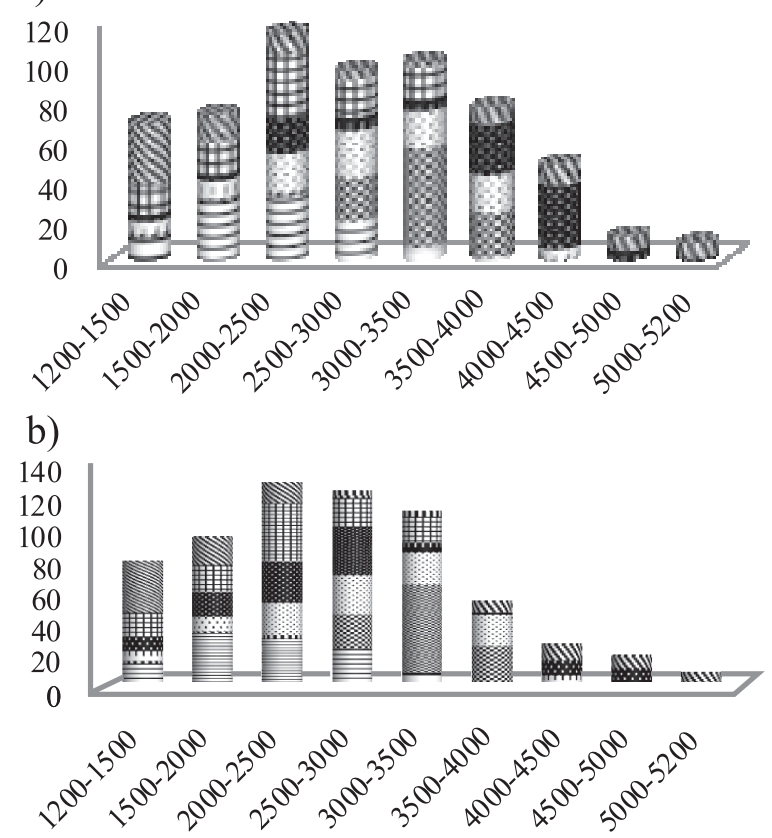

c)
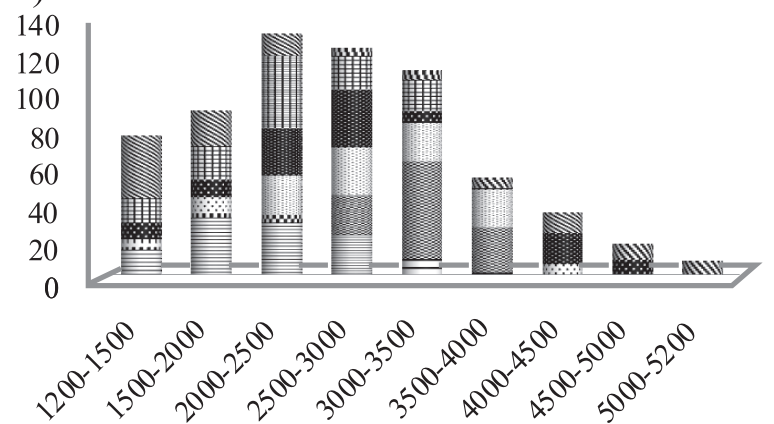

d)

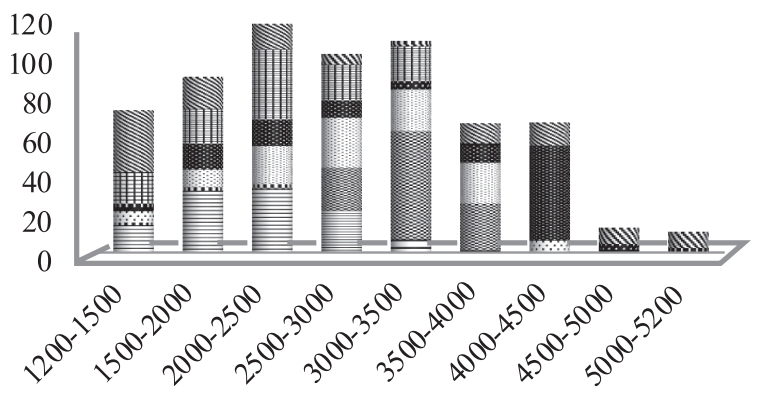

Fig. 3. Land use class distribution in each elevation partition: a) 1986 , b) 2000, c) 2006, d) 2015 .

\section{Results and Discussion}

\section{Spatial Distribution of Land Use Classes}

In the different EP, the total area ratio of land use classes from 1986 to 2015 is shown in Fig. 3. In the $1,200 \sim 1,500 \mathrm{~m}$ (I) EP, the main land use class was unused land, which accounts for $31.62 \%$ of total area of unused land in 1986 and $29.53 \%$ in 2015. In 1,500-2,000 m (II) EP, farmland occupied the most area $(30.16 \%$ in 1986 , $30.74 \%$ in $2000,29.37 \%$ in 2006 , and $29.38 \%$ in 2015 ), and other types had small proportion. From 2,000 to $5,200 \mathrm{~m}$, the main land use classes were different (urban and residential land (III), grassland, woodland and water body (IV), woodland (V), grassland and woodland, water body (VII), and unused land (VIII, VIIII)). Compared with the land use distribution, some vertical zonal pattern was reflected that farmland mainly distributed from 1,500-3,000 m, which contains II, III, and IV EP. Meanwhile, woodland was mainly distributed in the range of elevation from 2,500 to 4,000 m, which occupied about more than $90 \%$ of the total area of woodland. Grasslands mainly distributed in the range of III, IV, V, and VI EP from 1986 to 2015, which had two oasis regions and was surrounded by several rivers. Soil, temperature, and water were suitable for alpine grass growth in these EP, so grassland area was large. The water body was located mainly at an elevation of 4,000 $\mathrm{m}$ above, which came from the alpine rivers and meltwater. Comparatively, the urban and residential land was mainly distributed in the partition of 3,500 $\mathrm{m}$ below, especially in the III $(2,000-2,500 \mathrm{~m})$ EP, which accounts for $31.77 \%$ (1986), 34.58\% (2000), $36.82 \%$ (2006), and $33.43 \%$ (2015) of the total area of urban and residential lands, respectively.

Overall, from Qilian Mountain in the southern part to the desert area of the northern part, the distribution of the main land use types were shown as: glacier and perpetual snow $\rightarrow$ cold desert $\rightarrow$ water body $\rightarrow$ marsh $\rightarrow$ grassland $\rightarrow$ woodland $\rightarrow$ farmland $\rightarrow$ urban and residential land $\rightarrow$ bare soil $\rightarrow$ barerock $\rightarrow$ sandydesert $\rightarrow$ gobi. Along with altitude falling, various types of land use landscape overlaid one another and crossed distribution. The boundaries of land use classes gradually blurred from south to north.

\section{Spatial Position Conversion and Quantity Change of Land Use}

It could be reflected from Fig. 4 that the land use classes transferred obviously during the period of 2000-06 were mainly grassland, farmland, and unused land. Seen from position, grassland had changed across almost the entire study area (except some area that had no grassland) from downstream to upstream. However, the most obvious place was in the southeastern part of the study area, which was mainly converted into farmland and unused land. Meanwhile, farmland transfer mainly occurred in the upstream region, which was a minority place. The change of unused land mainly displayed in the downstream study area was from Fig 4 . This region had the most area of unused land such as bare soil, bare rock, sandy desert, and Gobi desert, as well as harsh environment.

The conversion area from 2006 to 2015 was also calculated using ArcGIS software (Table 1), where the area of farmland was $2,913.063 \mathrm{~km}^{2}$, of which the area converted into other classes was $1,402.47 \mathrm{~km}^{2}$, while others converted into farmland were $1,510.59 \mathrm{~km}^{2}$. In addition, grassland conversion area was $8,296.95 \mathrm{~km}^{2}$ (converted into $3,950.36 \mathrm{~km}^{2}$ as converted from $4,346.59 \mathrm{~km}^{2}$ ), and the woodland conversion area was 

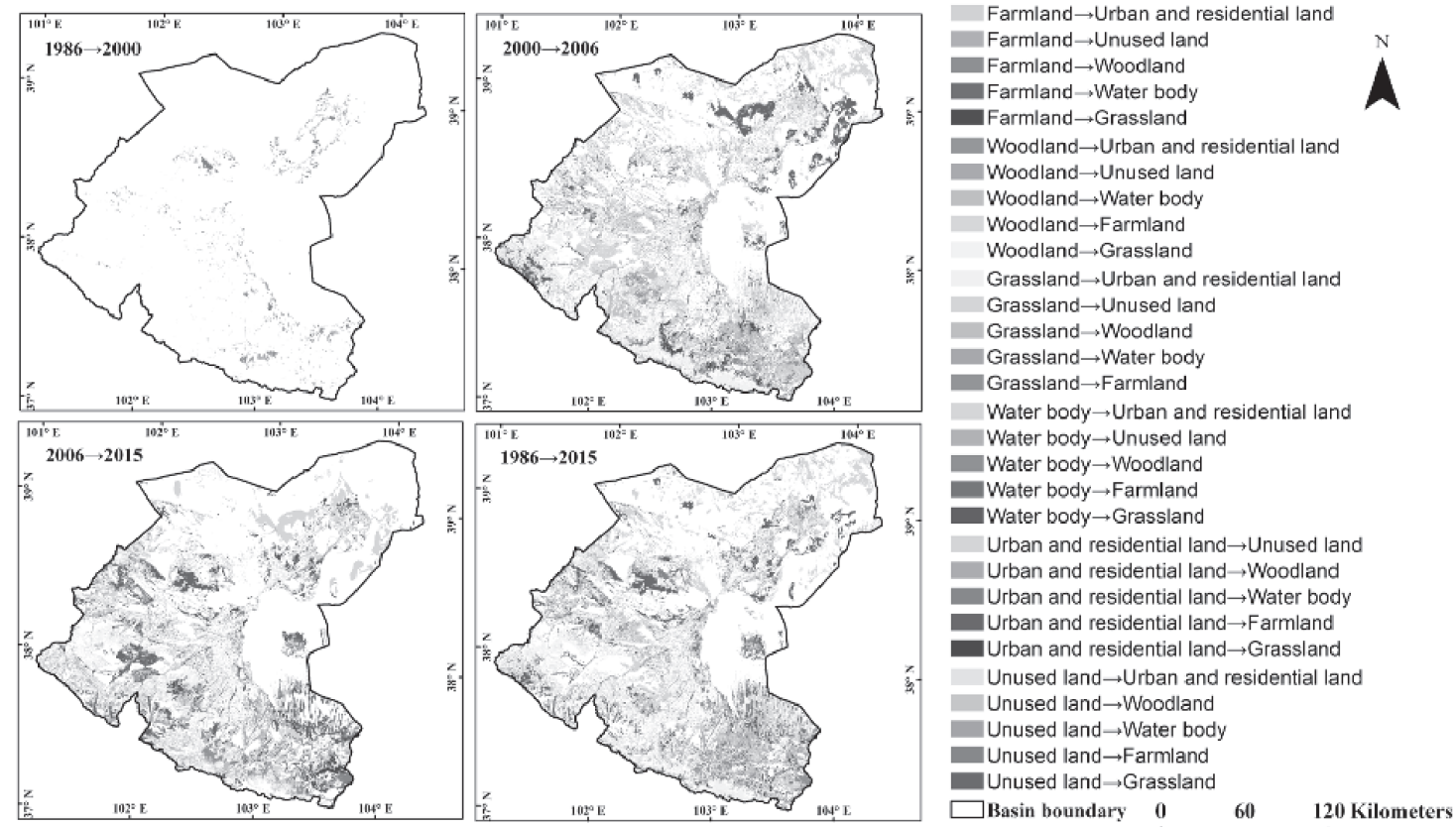

Fig. 4. Spatial distribution of land use conversion from 1986 to 2015.

2,550.11 $\mathrm{km}^{2}$ (converted into $1,374.97 \mathrm{~km}^{2}$ as converted from $1,175.14 \mathrm{~km}^{2}$ ). The smallest area change was surface water, with an area of $431.82 \mathrm{~km}^{2}$ (converted into $223.83 \mathrm{~km}^{2}$ as converted from $207.99 \mathrm{~km}^{2}$ ). From 2006 to 2015 , the biggest change area was grassland and the smallest was water.

\section{Spatial Temporal Change of Land Use in Different Circle Layers}

Fig. 5 shows that urban and residential land increased from the third to the $12^{\text {th }}$ circle layer, with the low-area ratio in 1986 and the high one in 2015, especially from the ninth circle layer, which increased intensely and which reflected that urban and residential land continually sprawled along the outside of the Shiyang River Basin in recent years. Furthermore, farmland area changed from the sixth to the $12^{\text {th }}$ circle layer, and the most obvious change happened in the $10^{\text {th }}$ circle layer, with areas of $108.53 \mathrm{~km}^{2}, 112.24 \mathrm{~km}^{2}, 198.59 \mathrm{~km}^{2}$, and $133.15 \mathrm{~km}^{2}$ from 1986 to 2015 . The $11^{\text {th }}\left(0.84 \mathrm{~km}^{2}, 0.83 \mathrm{~km}^{2}\right.$,
$0.85 \mathrm{~km}^{2}$, and $\left.0.96 \mathrm{~km}^{2}\right)$ and $12^{\text {th }}$ circle layers $\left(0.62 \mathrm{~km}^{2}\right.$, $0.60 \mathrm{~km}^{2}, 0.76 \mathrm{~km}^{2}$, and $0.90 \mathrm{~km}^{2}$ ) also changed a lot.

Grassland area changed differently in each circle layer, especially from the ninth to $12^{\text {th }}$ layers, with the ratio of the ninth circle at $21.88 \%, 21.73 \%, 27.17 \%$, and $29.22 \%$ from 1986 to 2015, respectively. From these results, some conclusions could be obtained as follows:

1. In Shiyang River Basin, urban and residential land, farmland, and grassland were the most intensely changed classes, while others were not so obvious.

2. Especially the sprawl of urban and residential land was heavily concentrated outside of the city center and kept the trend of increase during the period of 1986-2015.

3. Farmland changed in each circle layer and the area was mutually changed between increase and decrease. However, the total area of the farmland in the whole basin increased; in contrast, the area of grassland displayed a decreasing tendency in recent years, and the change mainly was presented at the edge of the basin.

Table 1. Land use conversion and quantity change in Shiyang River Basin (unit: $\mathrm{km}^{2}$ ).

\begin{tabular}{|c|c|c|c|c|c|c|c|}
\hline Converted into & $1986-2000$ & $2000-06$ & $2006-15$ & Converted from & $1986-2000$ & $2000-06$ & $2006-15$ \\
\hline Farmland & 105.90 & $1,856.73$ & $1,402.47$ & Farmland & 496.66 & $1,572.63$ & $1,510.59$ \\
\hline Woodland & 67.09 & $1,525.05$ & $1,374.97$ & Woodland & 21.14 & $1,246.27$ & $1,175.14$ \\
\hline Grassland & 295.03 & $5,896.98$ & $3,950.36$ & Grassland & 100.74 & $4,046.09$ & $4,346.59$ \\
\hline Water body & 1.63 & 68.62 & 223.83 & Water body & 3.67 & 216.83 & 207.99 \\
\hline $\begin{array}{c}\text { Urban and residential } \\
\text { land }\end{array}$ & 0.71 & 253.76 & 254.75 & $\begin{array}{c}\text { Urban and } \\
\text { residential land }\end{array}$ & 23.74 & 257.70 & 406.15 \\
\hline Unused land & 239.11 & $2,664.90$ & $3,611.82$ & Unused land & 63.52 & $4,926.51$ & $3,171.76$ \\
\hline
\end{tabular}


a)

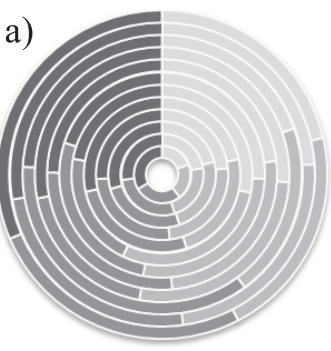

d)

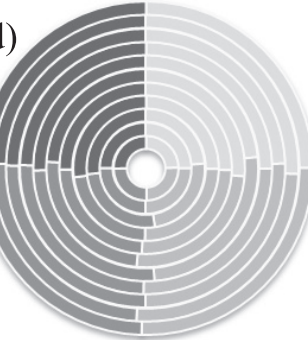

$1986=2000=2006 \square 2015$ b)

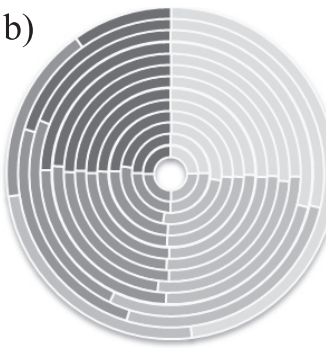

e)

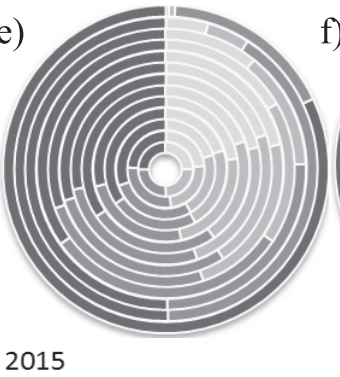

c)

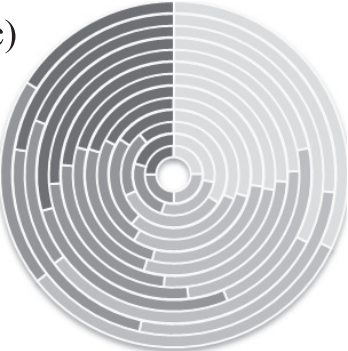

f)

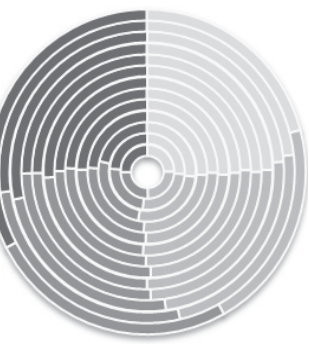

Fig. 5. Land use distribution in each circle layer, each of which is composed of the area ratios of 1986, 2000, 2006, and 2015; the change information can be indicated through proportions. a) farmland, b) woodland, c) Grassland, d) Water body, e) Urban and residential land, f) Unused land.

\section{Spatial Distribution Pattern Analysis of Land Use Classes}

In order to understand the spatial distribution of different land use class in different locations and directions, the circle layer and fan-shape were combined to analyze. Each fan-shaped zone was divided into concentric circles and the area in each circle layer and direction was computed (Fig. 6). The dominant land use classes were unused land, grassland, farmland, and woodland, which had the large area and patches. The largest area of land use was unused land, which distributed each circle layer and fan-shaped zone, especially when it had the most in the NE direction and the most widely distributed outside of the basin. Grassland was mainly distributed outside of the circle layer in NW from 1986 to 2015 and started decreasing after 2000. In contrast, the farmland was reclaimed nearby the midstream in SE, SW during the period of 1986-2000, and increased in the NE direction in 2006 while decreasing in 2015. Woodland distributed in SW and SE in 1986 and sprawled outside of the NW direction in 2000 and 2006, while shrinking SW in 2006.

\section{Result of Land Use Dynamicity Model}

Table 2 shows the result of the land use dynamicity model of land use class during the three periods of the Shiyang River Basin. Land use was kept stable before 2000, but experienced a significant dynamic change after 2000 from dynamic results. The most obviously changed class was urban and residential land, other classes such as farmland, grassland, and woodland also changed, while water body and unused land changed weakly. Urban and residential land expanded quickly after 2000, and more than 2\% growth average annual from 2000 to 2015. Farmland increased during the first and second periods (1986-2000 and 2000-06) and then decreased after 2006. It could be indicated from the expansion of urban and residential land and farmland that the change of land use of Shiyang River Basin was influenced obviously by human activities, for the demand of high quality for agriculture production and living environment. However, the increase of farmland and urban growth resulted in the loss of grassland and woodland.

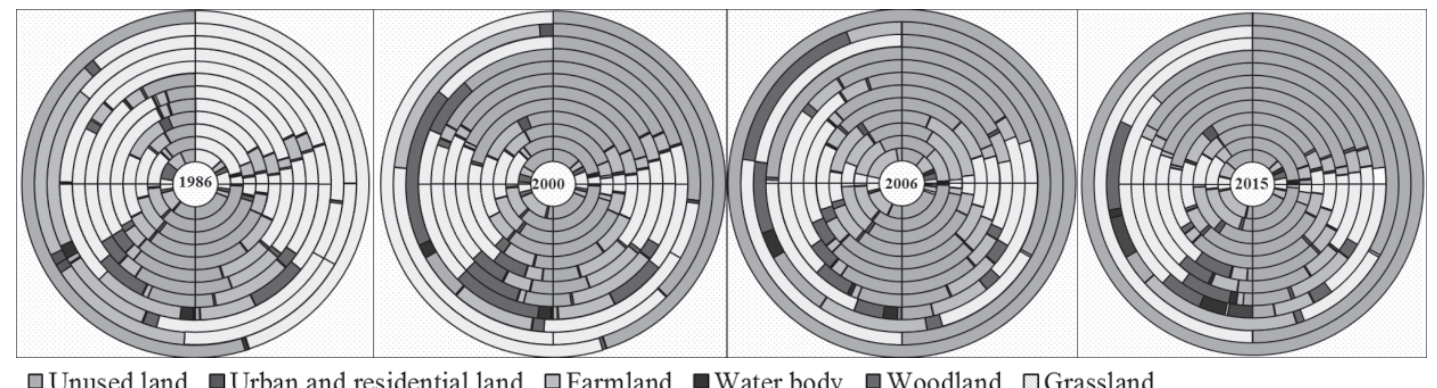

Fig. 6. Circle layer and fan-shaped temporal land use. 
Table 2. Area and dynamicity of land use class from 1986 to 2015 in Shiyang River Basin $\left(\mathrm{km}^{2}\right)$.

\begin{tabular}{|c|c|c|c|c|c|c|c|c|c|c|}
\hline \multirow{2}{*}{ Type } & 1986 & 2000 & 2006 & 2015 & \multicolumn{3}{c|}{ Dynamicity (\%) } & \multicolumn{3}{c|}{ Change Ratio (\%) } \\
\cline { 6 - 12 } & & & & & $1986-2000$ & $2000-06$ & $2006-15$ & $1986-2000$ & $2000-06$ & $2006-15$ \\
\hline Farmland & $6,507.42$ & $6,897.72$ & $7,032.62$ & $6,916.91$ & 0.42 & 0.32 & -0.23 & 0.06 & 0.05 & -0.04 \\
\hline Woodland & $2,676.49$ & $2,630.55$ & $2,521.82$ & $2,482.84$ & -0.12 & -0.68 & -0.22 & -0.01 & -0.04 & -0.01 \\
\hline Grassland & $11,280.10$ & $11,082.12$ & $11,031.23$ & $11,123.89$ & -0.13 & -0.07 & 0.12 & -0.03 & -0.02 & 0.03 \\
\hline Water body & 147.79 & 149.82 & 149.04 & 145.04 & 0.09 & -0.08 & -0.38 & 0.00 & 0.00 & -0.001 \\
\hline $\begin{array}{c}\text { Urban and } \\
\text { residential } \\
\text { land }\end{array}$ & 363.81 & 386.84 & 450.77 & 540.51 & 0.45 & 2.75 & 2.84 & 0.004 & 0.03 & 0.03 \\
\hline $\begin{array}{c}\text { Unused } \\
\text { land }\end{array}$ & $19,603.23$ & $19,431.78$ & $19,393.35$ & $19,369.65$ & -0.06 & -0.03 & -0.01 & -0.03 & -0.02 & -0.01 \\
\hline
\end{tabular}

\section{Major Driving Forces of the Land Use Spatio-temporal Change}

In the Shiyang River Basin, both natural conditions and human activities were responsible for land use changes, but the effect of human activities was more profound [16-17], especially population, policy, economic, and technological. The factors had a great influence on the change of most land use classes, especially farmland and urban and residential land [18]. Population growth had been considered a major factor leading to farmland change [19]. In 1986-2015 the population increased from $1,949,228$ to $2,429,066$ ( $24.61 \%$ increase), and the agriculture population increased from 1,644,391 to $1,805,142(9.77 \%$ increase $)$ as farmland area increased from $6,507.41$ to $6,916.91 \mathrm{~km}^{2}(6.29 \%$ increase $)$ and urban and residential land area increased from 363.81 to $540.50 \mathrm{~km}^{2}(48.56 \%$ increase). This indicates that population and human activities played an important role in land use change in the Shiyang River Basin [20].The increase of population would inevitably lead to an increase in demand of land production such as food, housing, and more [21].
Policies such as the China Western Development policy and New Countryside Construction strategies played a pivotal role in the area and spatial pattern change of the Shiyang River Basin (Fig. 7). Local residents were poor before 1986, and under the Economic Reform and Agriculture Production Campinas policy unused land reclamation was a way to get more food and money and greatly increase farmland area. With the construction of a family-contract responsibility system (the farmers have their own farmland), the area of farmland expanded and had become one of the key grain and corn production bases. China Western Development in the 2000s and the Agriculture Tax Canceling policy in 2006 were launched by the Chinese government. As a result, a large proportion of the wasted lands were reclaimed and a number of peasants worked in cities were back home again and began to make a living by farming. After 2000, the Grain for Green Project, Basin Comprehensive Planning, and Construction of New Countryside had a profound impact on the regional economy, land use constructions, and urban and residential land area. Consequently, policy was a complex factor that not only influenced land use area change, but

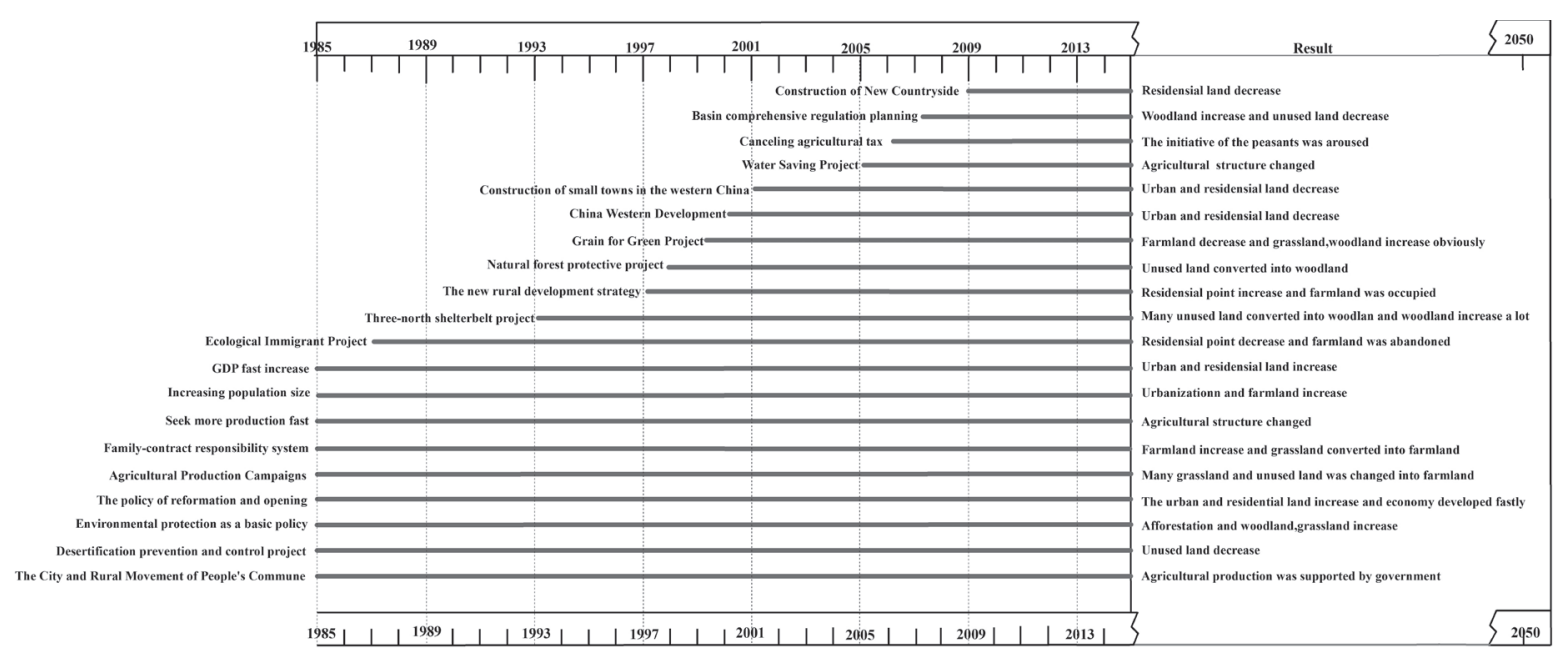

Fig. 7. China's major policy forces for and against land use change in the Shiyang River Basin. 
also forced various changes that both threatened and promoted the basin sustainable development.

\section{Conclusions}

This research showed that the main land use class was unused land, and distributed in the downstream plain, which was an average elevation of $1,500 \mathrm{~m}$ below. Farmland occupied the most area in 1,500-2,000 m (II) $\mathrm{EP}$, and woodland was mainly distributed in the range of elevation from 2,500 to $4000 \mathrm{~m}$, which occupied more than $90 \%$ of the total area of woodland. Because of the influence caused by terrain conditions, the patterns of land use distribution had an obvious vertical characteristic. The study found that farmland mainly took place at the intersection region between desert and agriculture oasis. In addition, the largest area of land use was unused land, which distributed each circle layer and fan-shaped zone, especially when it had the most in the NE direction and the most widely distributed outside of the basin, while other classes change occurred in each circle layer and directions. Although the dominant driving forces were population growth and policy, the fast development of the economy determined the land use patterns to a certain extent.

\section{Acknowledgements}

We gratefully acknowledge the support for this research by the National Natural Science Foundation of China (Nos. 41661084, 41471163, and 71263045), the Natural Science Foundation of Gansu Province (No. 1506RJZA129), and the Research Capability Improvement Program for Young Teachers of Northwest Normal University (No. SKQNYB14032).

\section{References}

1. DEFRIES R., ESHLEMAN K.N. Land - use change and hydrologic processes: a major focus for the future. Hydrological processes. 18 (11), 2183, 2004.

2. EPSTELN J., PAYNE K., KRAMER E. Techniques for mapping suburban sprawl. Photogrammetric engineering \& remote sensing. 63 (9), 913, 2002.

3. DITCHKOFF S.S., SALFELD S.T., GIBSON C.J. Animal behavior in urban ecosystems: modifications due to humaninduced stress. Urban Ecosystems. 9 (1), 5.2006.

4. JI W., MA J., TWIBELL R. W., UNDERHILL K. Characterizing urban sprawl using multi-stage remote sensing images and landscape metrics. Computers, Environment and Urban Systems. 30, 861, 2006.

5. TIAN H.Q., CHEN G.S., ZHANG C., LIU M.L., SUN G., CHAPPELKA A., REN W., XU X.F., LU C.Q.,PAN S.F. Century-scale responses of ecosystem carbon storage and flux to multiple environmental changes in the southern United States. Ecosystems. 15 (4), 674, 2012.

6. Li X.Y., XIAO D.N., HE X.Y., CHEN W., SONG D.M. Factors associated with farmland area changes in arid regions: a case study of the Shiyang River Basin, northwestern
China. Frontiers in Ecology and the Environment. 5 (3), 139, 2007.

7. ZHANG S.Q., AN F.Z., GUO Y.F. Research on land use change of Shiyang River Basin based on TM image. Environmental Protection of Xinjiang. 34 (1), 40, 2012.

8. MA J.Z., DING Z.Y., WEI G.X., ZHAO H., HUANG T.M. Sources of water pollution and evolution of water quality in the Wuwei basin of Shiyang river, Northwest China. Journal of environmental management. 90 (2), 1168, 2009.

9. ZHOU L.P., WEI H.D., DING F., CHEN F., HU X.K. Analysis of Land Use/Cover Chang in Shiyang River Basin During the Period of 1998-2005 .Bulletin of Soil and Water Conservation. 29 (1), 169,2009.

10. SHA Z., BAI Y., XIE Y., YU M., ZHANG L. Using a hybrid fuzzy classifier (HFC) to map typical grassland vegetation in Xilin River Basin, Inner Mongolia, China. International Journal of Remote Sensing. 29 (8), 2317, 2008.

11. WEI W., SHI P.J., ZHAO J., WANG X.F. Spatial relationship between elevation, vegetation cover and landscape types in Shiyang River Basin. Arid Land Geography. 35(1), 91, 2012.

12. MA J.Z., ZHANG P., ZHU G.F., WANG Y.Q., EDMUNDS W.M., DING Z.Y., HE J. The composition and distribution of chemicals and isotopes in precipitation in the Shiyang River system, northwestern China. Journal of Hydrology. 436, 92, 2012.

13. MA M.G., WANG X.M. Study on the oasis corridor landcape in the arid regions based on RS and GIS methods - application of JintaOasis,China. Journal of Environmental Sciences. 15 (2), 193, 2003.

14. LUO G.P., ZHOU C.H., CHEN X., LI Y. A methodology of characterizing status and trend of land changes in oases: A case study of Sangong River watershed, Xinjiang, China. Journal of environmental management. 88 (4), 775, 2008.

15. MITEAKIS N., TOPALOGLOU C., ALEXANDRIDIS T., THEOCHARIS J., ZALIDIS G. A novel self-organizing neuro-fuzzy multilayered classifier for land covers classification of a VHR image. International Journal of Remote Sensing. 29 (14), 4061, 2008.

16. LI Y., Qi X.M., DONG S.C., WANG L.L., FANG Y.D. Farmland use changes at oasis areas in the middle and lower reaches of Shiyang River Basin, Gansu Province of China. Transactions of the Chinese Society of Agricultural Engineering. 24 (4), 117, 2008.

17. ZHANG X.D., XIE Y.W., SHI J.Y., YUAN C.X. Change analysis of land use and landscape patterns in Shiyang River Basin. Journal of Lanzhou University (Natural Sciences). 5 (44), 19, 2008.

18. WEI W., SHI P.J., ZHOU J.J., WANG L.Y. Landscape pattern evolution in Shiyang River Basin based on GIS. Journal of Arid Land Resources and Environment, 2, 156, 2013.

19. MA J.Z., ZHANG P., ZHU G.F., WANG Y.Q., EDMUNDS W.M., DING Z.Y., HE J. The composition and distribution of chemicals and isotopes in precipitation in the Shiyang River system, northwestern China. Journal of Hydrology. 436, 92, 2012.

20. MA M.G., WANG X.M. Study on the oasis corridor landcape in the arid regions based on RS and GIS methods - application of JintaOasis,China. Journal of Environmental Sciences. 15 (2), 193, 2003.

21. WEI W., SHI P.J., ZHAO J., WANG X.F. Spatial relationship between elevation, vegetation cover and landscape types in Shiyang River Basin. Arid Land Geography. 1, 91, 2012. 